\title{
İntrauterin İnseminasyon Uygulanan Hastalarda Sperm Parametrelerinin Gebelik Sonuçları ile iliş̧kisi
}

\section{The relationship between sperm parameters and pregnancy outcomes in patients with intrauterine insemination}

\section{Cuma Taşın ${ }^{1 *} \square$, Gülnur Özakşit²}

${ }^{1}$ Sağlık Bakanlığı, Mersin Şehir Eğitim ve Araştırma Hastanesi, Kadın Hastalıkları ve Doğum Bölümü, Mersin ${ }^{2}$ Sağlık Bilimleri Üniversitesi, Ankara Şehir Hastanesi, Kadın Hastalıkları ve Doğum Bölümü, Ankara

\section{Öz}

Amaç: İnfertil hastalarda intrauterin inseminasyon yaygın kullanılan bir yöntemdir. Bu hastalardaki gebelik başarısını etkileyen sperm parametreleri ise hala tartışmalı bir konudur. Bu çalışmamız sperm parametrelerinin intrauterin inseminasyon sonuçlarına etkisini tayin etmeyi amaçlamaktadır.

Gereç ve Yöntem: Çalışmamız Ocak 2009-Ocak 2011 tarihleri arasında Dr. Zekai Tahir Burak Kadın Sağlığı Eğitim ve Araştırma Hastanesi infertilite polikliniğinde rekombinant FSH ile ovulasyon indüksiyonu oluşturulup intrauterin inseminasyon uygulanan 170 infertil hastanın 300 siklusunun incelendiği bir çalışmadır. Yaş, bazal FSH, toplam kullanılan FSH dozu, tedavi siklus sayısı, sigara kullanımı, varikosel ve semen parametreleri ile tedavi sonuçları karşılaştırıldı. Hastaların semen parametrelerinde total progresif motil sperm sayısı $\leq 10$ milyon ve $>10$ milyon , morfoloji ise $\leq \% 4$ ve $>\%$ olarak gruplara ayrıldı. Total progresif motil sperm sayısı ve morfoloji gruplarının gebelik sonuçlarına bakıldı. Erkek hastalarda sigara kullanımı ve varikoselin total progresif motil sperm sayısı ve morfolojiye olan etkilerine bakıldı.

Bulgular: Total progresif motil sperm sayısı $<10$ milyon ve $\geq 10$ milyon grupları arasında ve morfoloji $\leq \% 4$ ve $>\% 4$ grupları arasında klinik gebelik oranları açısından istatiksel olarak anlamlı fark saptanmadı. Erkelerde sigara kullanımının normal morfolojideki sperm sayısının azalttığı, varikoselin ise hem total progresif motil sperm sayısını hem de normal morfolojideki sperm sayısının azalttığı bulundu.

Sonuç: İntrauterin inseminasyon sikluslarındaki gebelik oranları ne tek başına morfoloji ne de tek başına total progresif motil sperm sayısı ile korelasyon göstermektedir. Infertil erkeklerde sigara kullanımının özellikle morfolojiyi bozarak gebelik oranlarını azalttığı saptandı. Varikoselin hem morfolojiyi hem de total progresif motil sperm sayısını azalttı̆̆ı fakat bunun gebelik sonuçlarını etkilemediği sonucuna ulaşıldı.

Anahtar Kelimeler: İntrauterin inseminasyon; sperm parametreleri; Total progresif motil sperm sayısı; morfoloji

Sorumlu Yazar*: Cuma TAŞıN, Sağlık Bakanlığı, Mersin Şehir Eğitim ve Araştırma Hastanesi, Kadın Hastalıkları ve Doğum Bölümü, Mersin 


\section{Abstract}

Aim: Intrauterine insemination is a widely used method in infertile patients. Sperm parameters that affect pregnancy success in these patients are still a problematic issue. This study aims to determine the effect of sperm parameters on intrauterine insemination results.

Material and Method: In this study; 300 cycles of 170 infertile patients who underwent intrauterine insemination after ovulation induction with recombinant FSH in the infertility outpatient clinic of the Dr. Zekai Tahir Burak Women's Health Training and Research Hospital between January 2009 and January 2011 were examined. Age, basal FSH, total FSH dose used, number of treatment cycles, smoking, varicocele, semen parameters and treatment results were compared. Patients were divided into groups as Total progressive motile sperm count $\leq 10$ million and $>10$ million, morphology $\leq 4 \%$ and morphology $>4 \%$ in semen parameters. Pregnancy results of total progressive motile sperm count and morphology groups were analyzed. In male patients, the effects of smoking and varicocele on total progressive motile sperm count and morphology from sperm parameters were evaluated.

Results: No statistically significant difference was found between the total progressive motile sperm count $\leq 10$ million and total progressive motile sperm count $>10$ million groups and between the morphology $\leq 4 \%$ and morphology $>4 \%$ groups in terms of clinical pregnancy rates. It was found that smoking in men decreased morphology, while varicocele decreased both total progressive motile sperm count and morphology.

Conclusion: Pregnancy rates in intrauterine insemination cycles show no correlation with either morphology alone or total progressive motile sperm count alone. It was found that smoking in infertile men decreased pregnancy rates by particularly disrupting the morphology. It was concluded that varicocele reduces both morphology and total progressive motile sperm count in male patients, but this does not affect pregnancy outcomes.

Keywords: Intrauterine insemination; sperm parameters; total progressive motile sperm count; morphology

\section{Giriş}

İnfertilite; çiftlerin en az 1 yıl süreyle düzenli, korunmasız ilişkisine rağmen gebelik oluşmamasıdır. Üreme çağındaki kadınların yaklaşık \% 15'ini etkilemektedir (1).

Infertilitenin etiyolojisinde \%20-40 ovulatuar disfonksiyonlar, \%30-40 tubo-peritoneal patolojiler ve \%30-40 erkek faktörleri suçlanmaktadır(1). Erkek hastalarda etiyolojik nedenler etkilerini genelde hastanın sperm parametrelerinde gösterir. Bu hastalarda hafif sperm faktörü olan hastalara fertiliteyi artırmak için IUI, daha ciddi olanlara ise IVF / İntrauterin sperm enjeksiyonu (ICSI) uygulanır. Spermatogenez sürecinde sperm hücresinde gelişen sayısal bozukluklar ve/veya şekil bozuklukları fertiliteyi olumsuz etkilemektedir. İdeal bir fertilite oranı için erkeğin semen analizinde $>40$ milyon / ejekülat (>\%50 motil) sperm hücresi ve bunların \% 14'ünün normal morfolojide olması gerekmektedir. İnfertil çiftlerin tedavisinde kullanılan yöntemlerden bir tanesi intrauterin inseminasyondur. Intrauterin inseminasyon (IUI); semenin laboratuvar ortamında ölü sperm, lökosit ve seminal plazmadan ayrıştırılarak hareketli ve normal morfolojideki spermlerin uterin kaviteye verilmesi işlemidir. IUI ucuz, basit ve daha az invaziv olması nedeniyle infertilite tedavisinde sıklıkla başvurulan yöntemlerden birisidir. Erkeğe bağlı infertilitesi olan çiftlerde IUı uygulanması konsepsiyon oranını artırmaktadır. Bu tedavinin başarısı her hastada aynı değildir. Başarıyı etkileyen temel prognostik faktörler hasta yaşı, infertilite süresi, total progresif motil sperm sayısı (TPMSS), morfoloji, endometrial kalınlık ve perovulatuar follikül sayısıdır (2,3.4). Bu hastalardaki konsepsiyon şansı oligosperminin derecesi ile orantılı olarak azalmaktadır (5). Daha önce yapılan çalışmalarda IUI uygulanan hastalarda en düşük gebelik oranı total sperm sayısı 5 milyonun altında olan hastalarda saptanmış (6). Yapılan diğer çalışmalarda da IUI uygulanan hastalarda TPMSS'nin gebelik sonuçlarında önemli olduğu sonucuna ulaşılmış (7).

Günümüzde kullanılan sperm parametrelerinden 2010 Dünya Sağlık Örgütü'nün önerdiği şekilde semen analizinde volüm, vizkozite, likefaksiyon süresi, total sperm sayısı, total motilite, progresif motil sperm sayısı, pH, sperm konsantrasyonu, morfoloji ve lökosit sayısı gibi parametreler bakılmaktadır. Sperm parametrelerinde bakılan morfoloji Kruger tarafından tanımlanmıştır (8)

Sperm kalitesinin azalmasına sebep olan birçok faktör olduğu bilinmektedir. Bunlardan sigara; yapısında bulundurduğu toksik maddeler ile sperm parametrelerini olumsuz etkiler (9). Diğer 
bir infertilite etkeni olan varikosel ise infertil erkeklerin yaklaşık \%21'ini etkilemektedir (10). İnfertil hastalardaki varikosel idiyopatik testis disfonksiyonuna neden olur (11).

Bu çalışmanın amacı; gebelik sonuçlarını etkileyebilecek , sperm parametreleriden morfoloji ve TMPSS başta olmak üzere, erkek ve kadın infertilite nedenlerinin değerlendirilmesidir.

\section{Gereç ve Yöntem}

Çalışmamız Ocak 2009 - Ocak 2011 tarihleri arasında Dr. Zekai Tahir Burak Kadın Sağlığı Eğitim ve Araştırma Hastanesi infertilite polikliniğinde rekombinant FSH (rFSH) ile ovulasyon indüksiyonu (OI) oluşturulup IUI uygulanan hastaların dosyalarının incelendiği retrospektif bir çalışmadır. Çalışmanın yapılabilmesi için Eğitim Planlama ve Koordinasyon (EPK) biriminden onam alındı. Çalışmaya en az bir yıl süreyle düzenli ilişkiye rağmen gebe kalamamış 20-40 yaş aralığında, FSH düzeyleri 10'un altında, vücut kitle indeksi < 35 olan ve infertilite faktörü olarak hafif erkek faktörü ve açıklanamayan infertilite tanısı almış çiftler alınmıştır. Bu kriterlere uygun 170 hasta bulundu, bu hastaların 300 tedavi siklusu incelendi. Infertilite araştırmaları için 3-7 günlük cinsel perhiz sonrası sperm analizi, adetin 3. günü yapılan hormonal analiz ve pelvik ultrasonografi, adetin 10. günü yapılan histerosalfingografi (HSG) temel testler olarak alındı. Oi için rFSH preparatları (Gonal-F, Serono \& Puregon, Organon, Türkiye) kullanıldı. 10. günden itibaren transvajinal folikülometri yapıldı. Ovulasyonu tetiklemek için en az bir tane $18 \mathrm{~mm}$ 'nin üzerinde follikül bulunması kriter olarak alındı. Hastalara ovulasyon amacıyla 10.000 IU hCG (Pregnyl flk, Organon, Türkiye) kullanıldı. Tüm sikluslarda hCG uygulandıktan 36 saat sonra hastalara tek inseminasyon yapıldı.

Çalışmada erkek infertilitesi için kullanılan semen parametrelerinde Dünya Sağlık Örgütü (WHO) kriterleri esas alınmıştır (8). Hastadan alınan sperm örneği için üç günlük cinsel perhiz önerildi. Örnekler steril kap içine alınarak likefaksiyon analizi yapıldı. İnseminasyon için kullanılacak motil spermatozoa temini için semen örneği, swim-up metodu; sperm sayısı düşük ve/veya lökospermi varlığında ise Percoll ile yıkanma yapıldı. IUI işleminde inseminasyon kateteri (Frydman;Laboratoir CCD, Paris, France) kullanıldı. Hastaların takibinde IUI'dan 12 gün sonra bakılan $\beta$ HCG değerleri $10 \mathrm{IU} / \mathrm{ml}$ 'den yüksek olup daha sonrasında azalan $\beta$ HCG değerleri olan hastalar biyokimyasal gebelik, takiplerde gebelik kesesi saptanan hastalar ise klinik gebelik olarak değerlendirildi.

Yaş, bazal FSH, toplam kullanılan FSH dozu, tedavi siklus sayısı, sigara kullanımı, varikosel ve semen parametreleri ile tedavi sonuçları karşılaştırıldı. Hastaların semen parametrelerinde
Total progresif motil sperm sayısı (TPMSS) $\leq 10$ milyon ve $>10$ milyon, morfoloji ise $\leq \% 4$ ve $>\% 4$ olarak gruplara ayrıldı. TPMSS ve morfoloji gruplarının gebelik sonuçlarına bakıldı. Erkek hastalarda sigara kullanımı ve varikoselin sperm parametrelerinden TPMSS ve morfolojiye olan etkilerine bakıldı. Çalışmanın istatistik analizinde IBM SPSS 19 programı kullanıldı. Verilerin dağılımı Shapiro Wilk testi ile değerlendirildi.Normal dağılım gösteren verilerin karşılaştırmasında ındependent Samples T Test,anormal dağılan verilerin karşılaştırmasında Mann-Whitney U Test test kullanıldı. Kategorik veriler Ki-Kare testi ile değerlendirildi. İstatistik sonucunda $P<0,05$ değeri anlamlı olarak kabul edildi.

\section{Bulgular}

Çalışmamızdaki 170 infertil hastaya 300 siklus IUI uygulanmış, toplam 44 gebelik elde edilmiştir. Oluşan gebeliklerin 37 tanesi klinik, 7 tanesi ise biyokimyasal gebelik şeklindeydi. Klinik gebelik oluşan grubun ortalama yaşı 27,9 olup diğer iki gruptan anlamlı olarak genç oldukları görüldü. Gebelik oluşmayan ve biyokimyasal gebelik oluşan iki grup hastanın yaş ortalamaları arasında fark görülmedi. Siklus sayısına göre gebelik oranı \% 14,6 (44/300) ve hasta sayısına göre hastaların yaklaşık \% 4,1'inde klinik gebelik , \% 21,8'inde biyokimyasal gebelik oluştu. Oluşan gebeliklerin siklusa göre oranına bakıldığında gebeliklerin \% 62,8'i i ilk siklusta , \% 20,6'sı ikinci siklusta ve \% 16,6'sı da üçüncü siklusta oluştu. Gebe kalan hastalar, gebe kalamayanlar ile yaş, bazal FSH, toplam alınan FSH açısından karşılaştırıldı. Hastaların gebelik sonuçlarına bakıldığında bazal FSH ve toplam gebelik siklusunda kullanılan FSH açısından anlamlı fark bulunmadı.

Sigara kullanmayan erkeklerin eşlerinde biyokimyasal gebelik oranı kullananların eşlerinden anlamlı olarak daha fazlaydı (sıra ile \% 27,1 ve \%3,5; $p=0,003$; Tablo 1 ). Gebelik sonuçları ile TPMSS, morfoloji ve erkekte varikosel ilişkisi saptanmadı.

Sperm parametrelerinden morfoloji sigara kullanan erkeklerde sigara kullanmayanlara göre anlamlı olarak azalmaktaydı (morfoloji $\leq \% 4$; sigara kullananlarda \% 25, kullanmayanlarda ise $\% 11 ; p=0,02)$. Diğer bir sperm parametresi olan TPMSS de sigara kullanan erkeklerde azalmasına rağmen ( sıra ile \% 12,5 ve $\% 7 ; p=0,24$ ) sonuçlar anlamlı değildi (Tablo 2 ).

Erkek hastalarda varikoselin sperm parametreleri ile ilişkisine bakıldığında varikosel mevcut hastalardaki morfoloji $\leq \% 4$ oranının varikoseli olmayan hastalardan anlamlı olarak fazla olduğu bulundu (sıra ile \% 43,3 ve \% $10 ; p=0,0001$ ). Aynı şekilde varikoseli bulunan erkek hastaların TPMSS $\leq 10$ milyon oranı varikoseli olmayan hastalardan anlamlı olarak daha fazlaydı (sıra ile \% 33,3 ve \% 3,6; $p=0,0001$ ) (Tablo 2). 
Tablo 1. Hastaların Özellikleri Gebelik Sonuçları iliş̧kisi

\begin{tabular}{|c|c|c|c|c|}
\hline & Gebelik yok (ort $\pm s d)$ & Klinik gebelik (ort $\pm s d$ ) & Biyokimyasal gebelik (ort $\pm s d$ ) & $P$ values \\
\hline Kadın yaşı & $29,2 \pm 4,2$ & $26,9 \pm 4,2$ & $29 \pm 3,1$ & 0,02 \\
\hline Bazal FSH & $6,13 \pm 1,17$ & $5,76 \pm 1,87$ & $6,14 \pm 1,77$ & 0,35 \\
\hline \multirow[t]{2}{*}{ Toplam Kullanılan FSH } & $853 \pm 35$ & $974 \pm 87$ & $878 \pm 116$ & 0,63 \\
\hline & Gebelik yok N(\%) & Klinik gebelik N(\%) & Biyokimyasal gebelik N(\%) & \\
\hline Erkek sigara kullanıyor & $49(87,5)$ & $5(8,9)$ & $2(3,5)$ & \multirow{2}{*}{0,003} \\
\hline Erkek sigara kullanmıyor & $78(68,4)$ & $5(4,3)$ & $31(27,1)$ & \\
\hline TPMSS < 10 milyon (siklus sayısı) & $25(80,6)$ & $4(12,9)$ & $2(6,5)$ & \multirow{2}{*}{0,68} \\
\hline TPMSS> 10 milyon (siklus sayısı) & $206(76,0)$ & $57(21)$ & $8(3)$ & \\
\hline Morfoloji $\leq \% 4$ (siklus sayısı) & $37(67,3)$ & $17(30,9)$ & $1(1,8)$ & \multirow{2}{*}{0,13} \\
\hline Morfoloji > \% 4 (siklus sayısı) & $194(78,5)$ & $44(17,8)$ & $9(3,7)$ & \\
\hline Varikosel var (hasta sayısı) & $24(80)$ & $4(13,3)$ & $2(6,7)$ & \multirow{2}{*}{0,36} \\
\hline Varikosel yok (hasta sayısı) & $102(72,9)$ & $33(23,6)$ & $5(3,5)$ & \\
\hline Toplam hasta sayısı & $126(74,1)$ & $7(4,1)$ & $37(21,8)$ & \\
\hline \multicolumn{5}{|l|}{$\mathrm{N}$ : hasta sayısı } \\
\hline
\end{tabular}

Tablo 2. Sigara ve Varikoselin Sperm Parametrelerinden Morfoloji ve TPMSS'ye Etkisi

\begin{tabular}{|c|c|c|c|c|c|c|}
\hline & $\begin{array}{c}\text { Morfoloji } \leq \% 4 \\
\mathrm{~N}(\%)\end{array}$ & $\begin{array}{c}\text { Morfoloji > \% } 4 \\
\text { N(\%) }\end{array}$ & $p$ values & $\begin{array}{c}\text { TPMSS } \leq 10 \text { milyon } \\
\mathbf{N}(\%)\end{array}$ & $\begin{array}{c}\text { TPMSS >10 milyon } \\
\mathbf{N}(\%)\end{array}$ & $p$ values \\
\hline Erkekte sigara kullanımı var & $14(25)$ & $42(75)$ & \multirow{2}{*}{0,02} & $7(12,5)$ & $49(87,5)$ & \multirow{2}{*}{0,24} \\
\hline Erkekte sigara kullanımı yok & $13(11)$ & $101(89)$ & & $8(7)$ & 106(93) & \\
\hline Varikosel var & $13(43,3)$ & $17(56,7)$ & \multirow{2}{*}{0,0001} & $10(33,3)$ & $20(66,7)$ & \multirow{2}{*}{0,0001} \\
\hline Varikosel yok & $14(10)$ & $126(90)$ & & $5(3,6)$ & $135(96,4)$ & \\
\hline
\end{tabular}

\section{Tartışma}

İnfertil hasta gruplarında kadın yaşının artması fertiliteyi olumsuz yönde etkilemektedir. İnfertilite hastalarında hasta tedavi şekli ve doğurganlık açısından kadın yaşı çok önemlidir. Van Noord-Zaadstra BM ve ark daha önce yaptığı bir çalışmada doğurganlık 25 ila 29 yaşlar arasında en yüksek değerde iken bu yaştan sonra dramatik bir şekilde azaldığını saptamıştır (12). Ingiltere'de yapılan bir çalışmada kadınlarda 30 yaşından sonra gebelik oranlarının azaldığı sonucuna ulaşılmıştır (13). Dilbaz ve ark. yaptığı bir çalışmada ise IUI uygulanan hastalarda en yüksek gebelik oranı 26 yaşının altında olan hastalarda elde edilmiştir (14). Yaş ile birlikte fertilitenin azalması, bu hastaların over dokusunda dominant folikül sayısının azalması ile açıklanabilir. Yaş ile beraber folikül sayısının azalması overi uyarıcı hipofiz hormonu olan folikül stimulan hormonun (FSH) artışına neden olur. Artan bu FSH değerleri hastanın fertilitesinin azaldığının bir göstergesidir (15). Bizim çalışmamızda da klinik gebelik oluşturan hastaların yaş ortalaması gebelik gelişmeyen hastalardan anlamlı olarak daha düşüktü ( sıra ile 26,9 ve 29,2).
Aynı şekilde klinik gebelik gelişen hastalardaki FSH değerleri diğer iki gruptan az olmasına rağmen bu sonuç anlamlı değildi.

Günümüzde infertil hastalarda hastanın özelliklerine göre farklı tedavi yöntemleri uygulanmaktadır. Kullanılan bu yöntemlerden bir tanesi de rFSH aracılığıla Oi ile spermin intrauterin inseminasyonudur. IUI tedavisi tek başına ya da Oi ile uygulanabilir. Hastaya uygulanan Oi, gebelik sonuçlarını olumlu yönde etkilemektedir (3). Goverde ve ark. yaptığı bir çalışmada gonadotropin ( $\mathrm{rFSH}$ ) ile birlikte IUI uygulanan hastalarda siklus başına gebelik oranı \% 8,7 bulunmuştur (4). Guziks ve ark. yaptığı bir çalışma (3) ve ESHRE'nin bir başka çalışmasında (8) ise siklus başına gebelik oranları sıra ile \% 17 ve \% 12 olarak bulunmuş. Başka bir çalışmada Burr RW siklus başına gebelik oranını \% 16.10 olarak elde etmiştir(16). Bizim çalışmamızda da diğer çalışmalara benzer olarak siklus başına gebelik oranı \% 14,6 olarak bulundu.

Daha önce yapılan bazı çalışmalarda en yüksek gebelik oranlarının ilk siklusta olduğu ve siklus sayısı artıkça gebelik oranlarının azaldığı sonucuna ulaşılmıştır (3). Başka bir çalışmada ise gebeliklerin 
genelde ilk üç siklusta oluştuğu, bu sikluslarda gebelik oluşmadı ise hastanın invitro fertilizasyona (IVF) yönlendirilmesi gerektiği sonucuna varılmış (17). Bizim çalışmamızda da daha önce yapılan çalışmalarla uyumlu olarak gebeliklerin \% 62,8'i ilk siklusta, \% 20,6'sı ikinci siklusta ve \% 16,6'sının üçüncü siklusta oluştuğu görüldü. Çalışma verileri değerlendirildiğinde siklus sayısı artıkça gebelik oranlarının azaldığı sonucuna varıldı.

Daha önce yapılan çalışmalarda sperm parametrelerinden morfoloji, TPMSS ve total motilitenin gebelik ile ilişkisi araştırılmıştır $(18,19)$. TPMSS sperm popülasyonunda ileri hareketli olan spermlerin sayısını ifade eder. IUI sikluslarında insemine edilen motil sperm sayısının minimum bir milyon olması gerektiği yönünde yayın olmakla birlikte (20) insemine edilen motil sperm sayısının <1 milyon, 1-2 milyon, 2-5 milyon, 5-10 milyon ve $\geq 10$ olarak sınıflandırıldığı bir çalışmada siklus sayısına göre gebelik oranları sırası ile \%3.13, \%8.67, \%11.89, $\% 14.75, \%$ ve 13.05 olarak bulunmuş (21). TPMSS'nin gebelik ile ilişkisini araştıran Ombelet ve ark. tarafından 10 milyonluk cut-off değerinin gebeliği predikte etmede kısıtlı olduğu ve sonucunun anlamlı olmadığı bulunmuştur (19). IUı hastalarında TPMSS ile gebelik arasındaki ilişkiyi çalışan farklı çalışmalar olmasına rağmen bu hastalardaki optimal değerler konusunda tam bir fikir birliği yoktur. Bizim çalışmamamızda TPMSS> 10 milyon olan grupta klinik gebelik oranının TPMSS $\leq 10$ milyon olan gruptan daha fazla olmasına rağmen grupların arasında anlamlı fark bulunmadı (klinik gebelik oranları sıra ile \% 21 ve \% $12.9 ; p=0,68$ ).

Diğer bir sperm parametresi olan morfolojinin IVF hastalarındaki etkinliği konusunda çalışmalar (17) olmasına rağmen, morfolojinin IUI uygulanan hastalardaki etkinliği net değildir. Lindheim ve ark yaptığı bir çalışmada sperm morfolojisinin IUI hastalarında gebelik sonucu ile ilişkili olduğu bulunmuş (22). Bunun dışında yapılan birçok çalışmada ise IUI uygulanan hastalarda sperm morfolojisi ve gebelik arasında ilişki bulunmamıştır $(23,24,25)$. Ayrıca sperm morfolojisinin Kruger kriterlerine göre \%4'ün üzerinde olmasının tek başına gebeliği predikte etmede yeterli olmadığını savunan görüşler de vardır (26). Nitekim bizim çalışmamızda, diğer bir çok çalışmada olduğu gibi, IUI hastalarında sperm morfolojisi ve gebelik sonuçları arasında ilişki bulunmadı.

Çalışmamızda erkekte sigara kullanımının fertilite üzerine etkisine bakıldı. Erkekte sigara kullanımı sperm hücresinde kreatinin kinaz aktivitesini azaltmakta; bu da sperm hücresinde morfoloji ve motilite değişikliğine neden olmaktadır (27). Bu nedenle sigara kullanan erkeklerin eşlerinde IUI sonuçlarını ve gebelik oranlarını düşürdüğü sonucu çıkarılmış (28). Sigaraya bağlı olarak sperm DNA'sında oluşan hasar motilite ve morfoloji ile ters orantılı olup bu hasar ovum tarafından tamir edilemeyen zigotlar oluşmasına neden olur (29). Sigara ayrıca DNA fragmantasyona ve artmış spontan abortusa neden olur (30). Yapılan başka bir çalışmada da sigaranın sperm morfolojisini bozduğu ve oligospermiye neden olduğu saptanmış (31). Axelsson ve ark. yaptığı bir çalışmada sadece aktif sigara içiminin değil, aynı zamanda pasif içiciliğin de sperm konsantrasyonunu azalttığı saptanmış (32). Beal ve ark. tarafından yapılan çalışmada sigaranın sperm sayısından çok DNA hasarına bağlı olarak yapı bozukluğuna (morfoloji bozukluğuna) sebep olduğu bulunmuş (33). Çalışmamızda sigara kullanmayan erkeklerin eşlerinde kimyasal gebelik oranının kullananlardan anlamlı olarak daha fazla olduğu görüldü ( sıra ile \% 27,1 ve \% 3,5). Çalışmamızda ayrıca sigaranın morfoloji ve TPMSS'ye olan etkisine bakıldı. Sigaranın diğer birçok çalışmada olduğu gibi bizim çalışmamızda da TPMSS'yi azatlığı bulunmasına rağmen sonuç anlamlı değildi. Çalışmamızda sigara asıl olumsuz etkisini sperm hücresinde oluşturduğu hasara bağlı olarak morfolojide göstermiştir. Sigara kullanan hastalarda morfolojinin azaldığı, morfoloji $\leq \% 4$ olan hasta grubunun sigara kullananlarda anlamlı olarak fazla olduğu bulundu. Çalışmamızdaki sonuçlar daha önce yapılan birçok çalışma ile uyumluydu.

Testis yapısındaki variköz venlerin genişlemesine varikosel denilir. Erkeklerde varikoselin bulunması infertilite riskini 2-3 kat artırmaktadır $(34,35)$. Genel popülasyonda varikosel sıklığı \% 4 ila \% 30 arasındadır. (35). Infertil erkeklerde yapılan çalışmalarda ise \% 17 ila \% 41 arasında olduğu bulunmuş (34). Sıklığındaki farklılıklar tanısının kişisel (öznel) koyulması ve tanıdaki kişisel farklılıklardan kaynaklanmaktadır. Dünya Sağlık Örgütü'nün 1992 yılında yaptığı çok merkezli bir araştırmada infertil erkeklerdeki varikosel oranının \% 6 ila \% 47 arasında olduğu ve coğrafi farklıklar gösterdiği bulunmuş (36). Bizim çalışmamızda da infertil hastalardaki varikosel oranı \% 17,6 (30/170) olarak bulundu. Erkek hastalardaki varikoselin sperm parametrelerini etkileyip etkimediği hala bir tartışma konusudur. Genel kanı değiştirmediği veya orta derecede astenospermi, teratospermi veya astenoteratospermi yaptığı yönündedir. Varikoselin başlangıcında sperm konsantrasyonuna etkileri ciddi değildir ancak ilerleyen dönemlerde sperm parametrelerinin tümü etkilenip azospermi ile sonuçlanabilir (37). Yakın zamanda yapılan bir çalışmada infertil varikoselli erkeklerin sperm parametrelerinin fertil erkeklerden daha az olduğu bulundu (38). Bu hastalardaki varikoselin mevcudiyeti düşük sperm konsantrasonu, artmış germ hücre apoptozisi, artan serbest radikaller ile ilişkilendirilmektedir (39). Yapılan başka bir çalışmada ise infertil erkeklerde varikosel varlığının sperm parametreleri üzerinde varikoseli olmayanlarla 
anlamlı bir fark oluşturmadığı bulunmuş (35). Dünya Sağıık Örgütü' nün yaptığı geniş ölçekli bir çalışmada erkekte varikoselin sperm konsantrasyonunu azatlığı bulunmuş fakat bu çalışmada varikoselin morfoloji ve hareketlilik konusunda kesin bir etkisinin kanıtına ulaşılamamış (36). Çalışmamızda erkekte varikoselin olmasının sperm parametrelerinden hem morfolojiyi hem de TPMSS'yi olumsuz yönde etkilediği bulundu. İnfertil erkeklerdeki varikoselin sperm parametrelerindeki olumsuz etkilerine rağmen IUI hastalarında gebelik sonuçlarını etkilemediği sonucuna ulaşıldı. Çalışmamızda farklı infertilite nedenlerinin bir arada değerlendirilmesi, erkek infertilitesinin ne sadece morfoloji ne de sadece TPMSS ile açıklanabileceğini göstermiştir. Çalışmanın limitasyonları ise tek merkezli ve retrospektif olmasıdır.

\section{Sonuç}

IUI sikluslarındaki gebelik oranları ne tek başına morfoloji ne de tek başına TPMSS ile korelasyon göstermektedir. Erkek hastalarda saptanan varikoselin sperm morfolojisi ve TPMSS'yi etkilemesine rağmen gebelik sonuçlarını değiştirmediği görülmektedir. Daha geniş tabanlı prospektif çalışmalar yapılarak IUI hastalarındaki optimal parametrelerin belirlenmesi uygun tedavinin zamanında verilmesini ve maddi kayıpların önüne geçilmesini sağlanacaktır.

\section{Çıkar çatışması}

Bu yazı tamamen bilimsel amaçla yazılmış olup, yazarların bu yazı ile ilgili herhangi bir çıkar çatışması bulunmamaktadır.

\section{Kaynaklar}

1. Fritz AM, Speroff L. Clinical Gynecologic Endocrinology and Infertility, 2011.

2. Tomlinson MJ, Amissah-Arthur JB, Thompson KA, Kasraie JL, Bentick B. Prognostic indicators for intrauterine insemination (IUI): statistical model for IUI success. Hum Reprod 1996; 11:1892-1896.

3. Guzick D, Sullivan M, Adamson GD, et al. Efficacy of treatment for unexplained infertility. Fertil Steril 1998; 70:207-213.

4. Goverde AJ, McDonnell J, Vermeiden JP, Schats R, Rutten FF, Schoemaker J. IUI or IVF in idiopathic subfertility and male subfertility. Lancet 2000; 355:13-18.

5. Kirby CA, Flaherty SP, Godfrey BM, et al. A prospective trial of intrauterine insemination of motile spermatozoa versus timed intercourse. Fertil Steril 1991; 56:102-107.

6. Berger T, Marrs RP, Moyer DL. Comparison of techniques for selection of motile spermatozoa. Fertil Steril 1985; 43:268-273.
7. DiMarzo SJ, Kennedy JF, Young PE, et al. Effect of controlled ovarian hyperstimulation on pregnancy rates intrauterine insemination. Am J Obstet Gynecol 1992; 166:1607-1612.

8. ESHRE Capri Workshop Group. Intrauterine insemination. Hum Reprod Update 2009; 15:265-277.

9. Sharpe RM. Environment, lifestyle and male infertility. Baillieres Best Pract Res Clin Endocrinol Metab 2000; 14:489-503.

10. Papadimas J, Mantalenakis S. Reproductive Endocrinology in males. Thessaloniki, University Studio Press, 1993.

11. Kantartzi P-D. [Update on the role of varicocele in male infertility]. Master degree dissertation. Thessaloniki, 2006.

12. Van Noord-Zaadstra BM, Looman CW, Alsbach H, Habbena JDF, te Velde ER, Karbaat J. Delaying child-bearing: effect of age on fecundity and outcome of pregnancy, Br Med J 1991; 302:1361-1365.

13. Shenfi eld F, Doyle P, Valentine A, Steele SJ, Tan S-L, Effects of age, gravidity and male infertility status on cumulative conception rates following artificial insemination with cryopreserved donor semen: analysis of 2998 cycles of treatment in one centre over 10 years. Hum Reprod 1993; 8:60-64.

14. Demir B, Dilbaz B, Cinar O, et al. Factors affecting pregnancy outcome of intrauterine insemination cycles in couples with favourable female characteristics. J Obstet Gynaecol. 2011; 31:420-423.

15. Barroso G, Oehninger S, Monzo A, Kolm P, Gibbons WE, Muasher Sj. High FSH:LH ratio and low LH levels in basal cycle day 3: impact on follicular development and IVF outcome. J Assist Reprod Genet 2001; 18:499-505.

16. Burr RW, Siegberg R, Flaherty S, Wang XJ and Matthews CD. The influence of sperm morphology and the number of motile sperm count inseminated on the outcome intrauterine insemination combined with mild ovarian stimulation. Fertil Steril 1996; 65:127-132.

17. A Nyboe Andersen, V Goossens, S Bhattacharya, et al. Assisted reproductive technology and intrauterine inseminations in Europe, 2005: results generated from European registers by ESHRE: ESHRE. The European IVF Monitoring Programme (EIM), for the European Society of Human Reproduction and Embryology (ESHRE). Hum Reprod 2009; 24:1267-1287.

18. Thonneau $P$, Marchand $S$, Tallec $A$, et al. Incidence and main causes of infertility in a resident population $(1,850,000)$ of three French regions (1988-1989). Hum Reprod 1991; 6:811-816. 
19. Ombelet W, Dhont $\mathrm{N}$, Thijssen A, Bosmans E, Kruger T. Semen quality and prediction of IUI success in male subfertility: a systematic review. Reprod Biomed Online 2014; 28:300-309.

20. Wainer R, Merlet F, Bailly M, Lombroso R, Camus E and Bisson JP. Prognosis for intrauterine insemination with partner's sperm according to the characteristics of the spermatozoa.Contracept Fertil Sex 1996;24:897-903.

21. Wainer R, Albert M, Dorion A, Influence of the number of motile spermatozoa inseminated and of their morphology on the success of intrauterine insemination Hum Reprod 2004;19:2060-2065.

22. Lindheim SR, Barad $D H$, Zinger $M$, et al. Abnormal sperm morphology is highly predictive of pregnancy outcome during COH and IUI. J Assist Reprod Genet 1996; 13:569-572.

23. Karabinus DS, Gelety TJ. The impact of sperm morphology evaluated by strict criteria on intrauterine insemination success. Fertil Steril 1997; 67:536-541.

24. Check ML, Bollendorf A, Check JH, Katsoff D. et al. Reevaluation of the clinical importance of evaluating sperm morphology using strict criteria. Arch Androl 2002; 48:1-3.

25. Lockwood GM, Deveneau NE, Shridharani AN, Strawn EY, Sandlow $\mathrm{JI}$. Isolated abnormal strict morpholohy is not a contraindication for intrauterine insemination. Andrology 2015; 3:1088-1093.

26. Van Waart J, Kruger TF, Lombard CJ, Ombelet W. Predictive value of normal sperm morphology in intra uterine insemination (IUI): a structured literature review. Hum Reprod Update 2001; 7:495-500.

27. Ghaffari MA, Rostami M. The effect of cigarette smoking on human sperm creatine kinase activity: as an ATP buffering system in sperm. Int J Fertil Steril 2013; 6:258-265.

28. İrez $T$, Ocal $P$, İdil $M$, et al. Effects of smoking cigarette on intrauterine insemination outcomes. Basic Clin Sci 2013;2:20-4.

29. Harlev A, Agarwal A, Gunes SO, Shetty A, du Plessis SS. Smoking and Male Infertility: An Evidence-Based Review. World J Mens Health 2015; 33:143-160.
30. Agarwal A, Majzoub A, Esteves SC, Ko E, Ramasamy R, Zini A. Clinical utility of sperm DNA fragmentation testing: practice recommendations based on clinical scenarios. Transl Androl Urol 2016; 5:935-950.

31. Jensen MS, Mabeck LM, Toft G, Thulstrup AM, Bonde JP. Lower sperm counts following prenatal tobacco exposure. Hum Reprod. $2005 ; 20: 2559-2566$.

32. Axelsson J, Rylander L, Rignell-Hydbom A, Silfver KÅ, Stenqvist A, Giwercman A. The Impact of Paternal and Maternal Smoking on Semen Quality of Adolescent Men. PLoS One. 2013; 8(6):e66766.

33. Beal MA, Yauk CL, Marchetti F. From sperm to offspring: Assessing the heritable genetic consequences of paternal smoking and potential public health impacts. Mutat Res 2017; 773:26-50.

34. Nieschlag E. Classification of andrological disorders In: Nieschlag E, Behre HM, eds. Andrology. Berlin, Heildelberg, New York: Spriger-Verlag 1997; 79-83

35. Redmon JB, Carey P, Pryor JL. Varicocele-the most common cause of male factor infertility? Hum Reprod Update 2002; 8:53-58

36. World Health Organisation. The influence of varicocele on parameters of fertility in a large group of men presenting to infertility clinics. Fertil Steril 1992; 57: 1289-1293

37. Peivandi S, Jafarpour $\mathrm{H}$, Abbaspour M, Ebadi A. Effect of letrozole on spermogram parameters and hormonal profile in infertile men: A clinical trial study. Endocr Regul 2019; 53:231-236.

38. Villanueva-Diaz CA, Vega-Hernandez EA, Diaz-Perez MA, et al. Sperm dysfunction in subfertile patients with varicocele and marginal semen analysis. Andrologia 1999; 31:263-267.

39. Zhang Y, Ma T, Su Z, Ye M, Tian H, Li J, Liu J. Varicoceles affect semen quality of infertile men in Southern China: A cross-sectional study of 5447 cases. Medicine (Baltimore). 2017; 96(31):e7707. 